\title{
ENTRE A NOVIDADE E A INSTITUCIONALIZAÇÃO DOS MOVIMENTOS SOCIAIS DE MORADIA
}

Patrícia Maria de Jesus

Resumo: A discussão apresentada é parte de investigação sobre uma política de habitação no Brasil denominada Programa Minha Casa Minha Vida e de suas relações com os movimentos sociais de moradia neste país. Nosso trabalho de campo e a revisão bibliográfica revelaram que os movimentos sociais de moradia fazem parte de diferente momento histórico e, consequentemente, de diferente concepção do que são e para que servem. Esses movimentos, juntamente com outros, são considerados "novos movimentos sociais". Atentos à recorrência com que nos deparávamos com essa qualificação, nos debruçamos sobre o sentido dessa novidade e de suas implicações práticas para a mobilização desses agentes, o que nos remeteu forçosamente a buscar compreender as dinâmicas de cooptação e institucionalização dos movimentos sociais. Eis os objetivos deste texto.

Palavras-chave: Programa Minha Casa Minha Vida, novos movimentos sociais, movimentos sociais de moradia, institucionalização.

\section{BETWEEN THE NEWS AND THE INSTITUTIONALIZATION OF HOUSING SOCIAL MOVEMENTS}

\begin{abstract}
The presented discussion is part of an investigation about a Brazilian housing policy known as Minha Casa Minha Vida (My Home My Life) and its relations to the housing social movements in Brazil. Our fieldwork and literature review revealed that housing social movements are part of a different historical moment and, therefore, of a different conception of what they are and what they were made for. These movements, along with others, are considered "new social movements". Paying attention to how many times we have seen ourselves in front of this qualification, we examined the meaning of this novelty and its practical implications for the mobilization of these agents. These examinations led us necessarily to seek for understanding about the dynamics of cooptation and institutionalization of social movements. These are the goals of this text.
\end{abstract}

Keywords: Minha Casa Minha Vida Program, New Social Movements, Housing Social Movements, Institutionalization.

\section{Introdução}

Os movimentos sociais como formas de contestação de uma ordem estabelecida surgem no século XIX no contexto do movimento operário europeu. As reivindicações eram fundamentalmente pautadas no conflito entre classes: trabalhadores $X$ proprietários, em convergência com orientações gerais que vão alicerçar as teorias marxistas, a partir do viés da exploração dos trabalhadores no chão da fábrica. Ainda que não tenhamos encontrado na literatura especializada "pistas" de que esses eram/foram os "movimentos sociais tradicionais", encontramos aí mesmo argumentos de que a abordagem de classes é absolutamente insuficiente para dar conta dos conflitos e insurgências na contemporaneidade, o que justifica uma nova abordagem para as novas ações, que são 
então pautadas como novos movimentos sociais. Voltaremos a isso adiante!

As teorizações sobre os novos movimentos sociais se pautam no estudo das teorias da ação social e das ações coletivas cujos maiores expoentes são os sociólogos francês Alain Touraine e espanhol Manuel Castells, cuja obra ecoa, por exemplo, nos estudos de Maria da Glória Gohn, socióloga brasileira, e Marcelo Lopes de Souza, geógrafo brasileiro, dois estudiosos do tema há várias décadas.

A tendência em naturalizar as análises e/ou a ausência de esforço analítico são os argumentos principais dos estudiosos que advogam em favor da diferenciação das ações coletivas, cujos movimentos sociais são apenas uma delas (GOHN, 2008) ou da diferença entre ações coletivas, movimentos sociais e ativismos sociais (SOUZA, 2009).

Em sua tentativa de conceituar os movimentos sociais, Maria da Glória Gohn (2008, p. 14) apresenta também seus elementos constituintes:

\begin{abstract}
Um movimento social é sempre expressão de uma ação coletiva e decorre de uma luta sociopolítica, econômica ou cultural. $E$ tem os seguintes elementos: demandas que configuram sua identidade, adversários e aliados, bases, lideranças e assessorias - que se organizam em articuladores e articulações e formam redes de mobilizações, práticas comunicativas diversas que vão da oralidade aos modernos recursos tecnológicos, projetos ou visões de mundo que dão suporte a suas demandas, e culturas próprias nas formas como sustentam e encaminham suas reivindicações.
\end{abstract}

Para Marcelo Lopes de Souza (2009), amparado em Touraine e Castells, "movimento é um termo que deve ser reservado para ações coletivas organizadas, de caráter público e relativamente duradouras e particularmente ambiciosas" (grifos do original). Para ele, o conceito intermediário entre ação coletiva e movimento é ativismo social. Assim, todo ativismo social é uma ação coletiva, mas nem toda ação coletiva é um ativismo, e todo movimento social é um ativismo, mas nem todo ativismo é um movimento social (p. 10). Em suas palavras:

Um verdadeiro movimento social possuiria um elevado senso crítico em relação ao status quo, (revelando capacidade de levar em conta fatores estruturais e de articular isso com análises de conjuntura, e procedendo à denúncia de problemas profundos como exploração de classe, racismo, opressão de gênero etc.), nisso ele se distinguiria, por exemplo, de ações coletivas coordenadas por organizações clientelistas e com horizonte reivindicatório pouco exigente (ou até mesmo manipuladas por políticos profissionais), como tem sido o caso de muitas associações de moradores (loc. cit.) (grifos do original).

Ante formulações malacabadas e pouco sólidas sobre o conceito de movimento social, seus estudiosos anunciam descontentamentos e limites. Marcelo Lopes de Souza (2009, p. 11) critica o uso indiscriminado da expressão movimento social:

Não ficaríamos conceitualmente um pouco desarmados se, em nome de uma recusa de um determinado tipo de apriorismo conceitual rigidamente discriminatório, simplesmente aplainássemos o terreno e utilizássemos o mesmo termo técnico e o mesmo conceito para dar conta de coisas às vezes bem diferentes, no que se refere à sua dinâmica, aos seus propósitos explícitos, ao seu grau de questionamento deliberado do status quo e às suas implicações? 
Segundo Gurza Lavalle, Castello e Bichir (2004):

Como boa parte dos conceitos que visam a conectar formas específicas da ação coletiva com reflexões teóricas acerca das suas implicações para a racionalização do poder, para a ampliação da democracia e do espaço público ou para a emancipação social, a ideia movimentos sociais apresenta problemas de ambiguidade na sua definição. O termo tem sido utilizado igualmente na definição de atores empíricos específicos, normalmente portadores de capacidade de contestação perante o Estado Movimento dos Sem-Teto (MST), Movimento dos Atingidos por Barragens (MAB) -, e na unificação analítica de conjuntos esparsos de iniciativas individuais e coletivas orientadas de modo diacrônico por afinidades de sentido em torno de temas específicos - movimento feminista, movimento negro, movimento de moradia, movimento de saúde. Não existem dúvidas quanto ao mérito heurístico da segunda utilização para uma sociologia da ação coletiva e da transformação social, porém, sua operacionalização é extremamente complexa (p. 47, grifos do original).

Maria da Glória Gohn (2008), denuncia a lacuna na produção acadêmica a respeito dos movimentos sociais questionando não só o conceito, mas também o que o qualifica como novos; o que diferencia suas ações das ações de outras organizações, qual 0 papel desses movimentos no século XXI, dentre outras problematizações (p. 14).

Estamos certos, portanto, de que tais lacunas resvalam direta ou indiretamente em nosso esforço de compreender os movimentos sociais de moradia em sua interlocução com o Programa Minha Casa Minha Vida, não por questões terminológicas, ${ }^{1}$ (pois se autores de sabida experiência e dedicação sobre o tema não encontraram ainda a acuidade necessária, nos vemos então diante de um debate ainda em franca disputa), mas sabidamente, as questões que essas ausências evocam fazem parte também de nossas dúvidas, caso contrário, a proposição dessa investigação não faria sentido.

Durante as entrevistas com as lideranças das Entidades Nacionais de Luta por Moradia um consenso veio à tona: o surgimento delas no período de transição entre a Ditadura Militar e a democratização do país. Fez sentido para nós então, buscar contribuições teóricas elaboradas neste período ou que fizessem referência a ele. ${ }^{2}$

Voltamos agora ao argumento da emergência dos novos movimentos sociais, dos quais fazem parte o movimento social de moradia.

Ernesto Laclau escrevia em 1986 que as categorias de "classe trabalhadora" e "pequeno burguês" possuíam significado cada vez mais reduzido como forma de entendimento da identidade global dos

\footnotetext{
1 Nos trabalhos analisados, há diferentes termos para a temática em tela: movimentos reivindicatórios urbanos (JACOBI, 1989), movimentos sociais urbanos (RODRIGUES, 1992; SOUZA, 2009), movimentos populares urbanos (RODRIGUES, 2007), nova sociedade civil (GURZA LAVALLE; CASTELLO; BICHIR, 2004), movimentos sociais emancipatórios (SOUZA, 2010). Disso consideramos que, mesmo antes de resolvida (se é que se pode resolvê-la) a questão do rigor conceitual acerca do termo "movimentos sociais", há tentativas de novas formulações. Na Geografia, como veremos adiante, há também um debate na proposição de novos termos e definições como movimentos socioespaciais e movimentos socioterritoriais, que buscam se desvencilhar tanto quanto possível das matrizes sociológicas e trazem para o campo de discussão as variáveis espaço e território - seminais para a Geografia.

2 Evers (1984), Laclau (1986), Jacobi (1989), Sader (1989), Gurza Lavalle, Castello e Bichir (2004), Gohn (2008), Souza (2009; 2010).
} 
agentes sociais, e que o conceito de "luta de classe" não era correto, tampouco incorreto, apenas insuficiente para contemplar e descrever os conflitos sociais, sobretudo na América Latina, onde uma análise rígida de classes nunca abarcou as especificidades de suas sociedades (LACLAU, 1986, p. 44 e seguintes.)

Também Gohn (2008) reconhece que na contemporaneidade, os movimentos sociais são diferentes daqueles irrompidos no século XIX e nas primeiras décadas no século $\mathrm{XX}$ como, por exemplo, o movimento operário e movimentos revolucionários desde a Revolução Francesa, ou os movimentos americanos dos anos 1960 (direitos civis, feminismo, estudantil, contra a Guerra do Vietnã) (GOHN, 2008, p. 11.)

Gurza Lavalle, Castello e Bichir (2004) igualmente localizam a emergência dos novos movimentos levando em conta a insuficiência de preceitos exclusivamente marxistas, além disso, relacionam a manifestação desses atores ao período de exceção:

[...] novos sujeitos capazes tanto de revitalizar a ação social para além do figurino rígido prescrito pela luta de classes, quanto de exprimir a inconformidade de diferentes segmentos da sociedade perante a política silenciária operada pela ditadura (p. 38, grifos nossos).

Buscando chaves interpretativas para a novidade dos movimentos sociais, deparamo-nos com questionamentos sobre o caráter crítico e mutante dos paradigmas analíticos das ciências sociais. Vejamos:

O pensamento acadêmico parece ter sucumbido, assim, a um velho dilema da construção de conceitos: se, de um lado, o horizonte da transformação social, da emergência de processos inéditos apenas tornase acessível mediante a reforma do pensamento e a criação de novas ideias capazes de capturar o nuvum no mundo, de outro, é difícil elucidar até que ponto não é a própria mudança de perspectiva analítica que produz um efeito de novidade sobre fenômenos preexistentes (GURZA LAVALLE; CASTELLO; BICHIR, 2004).

Laclau (1986), tentando responder à questão sob que aspectos os movimentos sociais são novos, relaciona essa mudança com a crise de um paradigma tradicional das Ciências Sociais, que caracterizaria os agentes sociais tipificados através de três características: a) a identidade dos agentes, b) o tipo de conflito, e c) o espaço político unificado. Após analisar cada uma dessas características conclui: "O que caracteriza os novos movimentos sociais, então, é que, através deles, rompeu-se a unidades destes três aspectos" (p. 41).

Tilman Evers (1984) pondera: "Não é apenas que a realidade esteja mudando: ela está fugindo a nossos modos de percepção e a nossos instrumentos de interpretação ( $p$. 11). E Gohn (2008, p. 11) ainda considera:

A preocupação com a teorização sobre os movimentos sociais ocorre porque, por um lado, eles ganharam visibilidade na própria sociedade na qualidade de fenômenos históricos concretos. Por outro, o desenvolvimento das teorias sobre o social colocou as ações coletivas num outro patamar, num universo mais amplo, reconstruindo e construindo novas teorias sobre a sociedade civil.

A partir disso, quais são então as características dos novos movimentos sociais? A primeira diferença básica entre os "tradicionais" e os "novos" é que, se os primeiros buscavam reivindicar algo estruturante e universal (a ruptura da luta de 
classes no decurso do modo de produção capitalista que nos atingiria a todos de igual maneira e que por isso deveria ser combatido), os segundos amparam-se em lutas e interesses particulares, em diferenciados setores da sociedade civil. Isso num primeiro momento, pois veremos que, com o passar do tempo, quando os movimentos ganham notoriedade e legitimidade, se é "impossível" lutar contra o Estado, é possível pressioná-lo para que sejam atendidas suas demandas, e assim os movimentos agem ao longo das décadas de 1980 e 1990. Mais recentemente, de 2000 em diante, sua luta por espaços institucionais "obrigou" o Estado a não mais "evitá-los", ao contrário disso, "convidá-los" à participação. Daí decorrerá inclusive, a difícil e contraditória relação entre ambos e ao que os intelectuais chamarão de institucionalização dos movimentos que não concorrerá para o seu fortalecimento, mas para o seu enfraquecimento, ou para seu refluxo. Assunto que debateremos com mais rigor no último subitem deste texto.

Sobre as características desses movimentos Tilmam Evers (1984, p. 14) destaca:

[...] um número relativamente baixo de participantes, estruturas não burocráticas e até informais, formas coletivas de tomada de decisões, distanciamento social relativamente pequeno entre liderança e demais participantes, modos pouco teóricos e imediatos de perceber e colocar os objetivos do movimento etc.

Discutindo a pluralidade do social, Ernesto Laclau (1986, p. 43) identifica:

A característica central deles, [...] é que um conjunto de posições de sujeito (em nível de local de residência, aparatos institucionais, várias formas de subordinação cultural, racial e sexual), tornaram-se pontos de conflito e mobilização política. A proliferação destas novas formas de luta resulta da crescente autonomização das esferas sociais nas sociedades contemporâneas, autonomização essa sobre a qual somente se pode obter uma noção teórica de todas as suas implicações, se partirmos da noção do sujeito como um agente descentralizado destotalizado.

Rodrigues (1992) enfatiza a visibilidade política dos movimentos com relação a suas demandas, que surge do que a autora chama nesta e em outras contribuições (a exemplo de RODRIGUES, 2007) de desalienação coletiva, ou seja, o processo pelo qual um grupo de pessoas privado de seus direitos, os reconhecem a partir das identificações no âmbito do coletivo na tentativa de evidenciar, denunciar e lutar por seus problemas.

A mesma autora, em artigo escrito em 2007, destaca:

Enquanto os trabalhadores, no âmbito das lutas na fábrica, dirigem-se diretamente aos capitalistas, os movimentos de moradia dirigem-se diretamente ao Estado, responsável, segundo as normas constitucionais, a garantirem a reprodução da vida, estabelecer e fazer cumprir parâmetros para a ocupação do solo, garantir a função social da cidade e da propriedade (p. 9).

Comparando os novos movimentos sociais com os de outrora, Gohn (2008) chama atenção para a mudança de uma perspectiva geral para a particular, o que nos remete à "autonomização" a que se refere Laclau (1986):

Naquela década [1980], os movimentos lutavam pelo direito de ter direitos. Como só podemos falar em direitos se contemplamos 0 universal, aqueles movimentos não 
estavam autocentrados, não miravam apenas a si próprios. Na atualidade, muitos dos novíssimos movimentos, ou ações civis denominadas movimentos, não têm mais o universal como horizonte, mas sim o particular, os interesses imediatos, 0 direito de sua categoria ou grupo social (GOHN, 2008, p. 12, grifo do original).

Em contato com a literatura aqui referida, demos conta também de um relativo "sumiço" dos movimentos sociais na década de 1990 Gomes (2010), Gurza Lavalle, Castello e Bichir (2004), e de seu ressurgimento nas duas últimas décadas Souza $(2009 ; 2010)$.

Porque os movimentos teriam entrado em refluxo na década de 1990, se este decênio é exatamente posterior àquele em que houve a efervescência desses movimentos no contexto das carências socioeconômicas situadas na "década perdida", e também no contexto da transição democrática brasileira?

Não por acaso, é nessa década que iniciamos a experimentação em solo brasileiro do projeto neoliberal. Teria esse fato influenciado direta e/ou indiretamente as práticas dos movimentos e o consequente "abandono" do tema no referido período?

São fatores para o esfriamento das práticas dos movimentos de acordo com Gurza Lavalle, Castello e Bichir (2004):

- a exaustão e o desgaste inerente ao ativismo de atores que não atingem patamares de institucionalização capazes de estabilizá-los,

- a institucionalização e a cristalização desses atores sob lógicas corporativas, ou seja, a desmobilização ocasionada não pelo desgaste, mas pela cooptação,

- a emergência de novas formas organizativas a conquistarem a centralidade outrora característica dos movimentos sociais.

Souza (2009, p. 13), preocupado em descortinar o renovado interesse acadêmico pelo tema destaca:

Os anos 1990 assistiram a um relativo desinteresse pelo tema dos ativismos urbanos no Brasil. Isso foi particularmente nítido na Geografia, mas também teve lugar, em menor escala, entre os sociólogos. No que concerne à Geografia, especificamente, 0 interesse pelos ativismos sociais nunca havia sido mesmo lá muito grande, mas a década de 1980 testemunhara (com um atraso de alguns anos em relação à Sociologia brasileira) um certo interesse pelo assunto.

Para imediatamente a seguir ponderar o fato de a temática estar de volta às rodas de discussões: "a primeira década do novo século vem demonstrando um renovado, embora ainda tímido, interesse dos geógrafos urbanos brasileiros pelo tema" (loc. cit.).

Esse autor chama ainda atenção para a relação que há entre a força dos ativismos (entendidos como visibilidade política) e o interesse acadêmico por eles, de modo a questionar que quando estão enfraquecidos ou em refluxo são abandonados, quando em sua opinião, razões como essas seriam primordiais exatamente para enriquecer os estudos acadêmicos e as formulações sobre eles. 


\section{Movimentos sociais e Geografia}

Doravante, nos basearemos no elucidativo artigo de Nelson Pedon intitulado A pesquisa geográfica sobre os movimentos sociais: balanço e perspectivas, em que o autor se dedica precisamente em acompanhar o desenvolvimento dos movimentos sociais como tema na Geografia.

De acordo com ele, o interesse desta ciência pelos movimentos sociais coincide com a renovação proposta pela Geografia Crítica que representou não só uma mudança analítica pautada na relação dos homens com o seu espaço, tendo o materialismo histórico geográfico como referencial teórico base, mas também uma ampliação da perspectiva geográfica que passou a se preocupar com assuntos antes tratados exclusivamente por outras ciências.

São duas as razões elencadas por ele para a Geografia voltar-se para o estudo desses movimentos: a) a projeção de um expressivo número de movimentos sociais que vinham conquistando espaços políticos essenciais para suas reivindicações e b) a incorporação de uma matriz teórico-metodológica que permitisse à Geografia mudar o eixo de sua análise, considerando o homem não apenas como um elemento da paisagem, mas como sujeito de sua história. Aqui é importante notar que a primeira razão que Nelson Pedon aponta para justificar os estudos dos movimentos sociais na Geografia corrobora o raciocínio desenvolvido por Marcelo Lopes de Souza e que fizemos referência parágrafos atrás, para quem há relação entre a força política dos movimentos e o interesse da academia em estudá-los.

Localiza nos trabalhos de Manuel Correia de Andrade de 1963 ( $A$ terra e o homem no nordeste) e de Josué de Castro de 1964 (Sete palmos de terra e um caixão: ensaio sobre o Nordeste área explosiva) a "pré-história" dos movimentos sociais na Geografia. São tidos por ele como os precursores dos estudos com esse viés: ambos denunciando a situação de sujeição do homem e da terra a um modelo de desenvolvimento do capitalismo baseado na grande propriedade e submissão aos interesses internacionais. Esses estudos relacionaram então a ausência da reforma agrária no país e a organização social com o objetivo de reivindicar mudanças no quadro agrário brasileiro (p. 69). Vemos aí, mesmo sem a formulação que virá posteriormente o inerente conflito entre o aparelho estatal e as mobilizações populares.

Para Nelson Pedon questões fundamentais para as investigações sobre os movimentos sociais estão presentes nas duas obras: espacialização, interação com outros setores da sociedade, ação dos mediadores, perspectiva de totalidade (p. 70).

Para subsidiar sua reflexão recorreu a um levantamento bibliográfico em publicações periódicas importantes para a Geografia de acordo com os períodos por ele analisados. Para o decênio 1960 e 1970 pesquisou o Boletim Paulista de Geografia (organizado pela AGB) e a Revista Brasileira de Geografia (organizada pelo IBGE). Neste período, não há segundo ele, nenhum artigo publicado sobre movimentos sociais. Os temas predominantes são aqueles clássicos da Geografia como, por exemplo: processos de urbanização, funções regionais e zonas de influência, localidades centrais, agricultura e capital, desenvolvimento agrícola, mapeamento de informações geográficas etc. Disso concluímos que os ecos da renovação 
da Geografia propalada a partir do Encontro Nacional de Geógrafos de 1978 não estão ainda incorporados no período, o que justifica a ausência do tema em debate nos periódicos pesquisados.

No período de 1970 e 1980:

O movimento sindical e o conjunto das ações coletivas que ocorriam, principalmente nas metrópoles, foram analisados a partir do paradigma marxista clássico das lutas de classe e da relação classe-Estado. Não obstante a essa influência marxista, os quadros explicativos que surgiram ampliaram as perspectivas para além das análises da inserção dos sujeitos no sistema de produção, apontando as potencialidades geradoras da transformação a partir da inserção dos setores mobilizados na esfera da reprodução social (PEDON, 2009, p. 71 , grifos nossos).

Para a década de 1980 e 1990, foram pesquisados os seguintes periódicos: Boletim Paulista de Geografia, Boletim de Geografia Teorética, Boletim Goiano de Geografia, Caderno Prudentino de Geografia e a Revista Terra Livre. Em suas palavras, esses periódicos (todos de vinculação nacional) representaram as tendências e temáticas da Geografia brasileira na década de 1980. Para ele, é nesta década que de fato se valoriza o tema no campo da Geografia.

No Boletim de Geografia Teorética destacam-se o conjunto de textos publicados em 1992, por ocasião do II Simpósio Nacional de Geografia Urbana que derivaram da mesa redonda "Cidades e Movimentos Sociais", dos quais são exemplos os artigos de Ana Fani Carlos que pauta os movimentos sociais com o espaço da cidade, Arlete Moyses Rodrigues relacionando os movimentos sociais urbanos com questões relativas à habitação, e também a conflituosa relação entre os movimentos sociais e Estado de José
Borzacchiello da Silva; e Jan Bitoun propondo questões importantes para a Geografia Urbana a partir do par movimento social e cidade. ${ }^{3}$

Quanto ao Boletim Goiano de Geografia, Nelson Pedon encontra apenas um artigo que trata indiretamente do tema, além de salientar que nessa década o periódico em questão não teve ampla circulação em território nacional.

É no Boletim Paulista de Geografia que no período analisado está o maior número de artigos dedicados à temática, nos anos de 1980, 1984, 1985. O autor examina com minúcia os artigos relevantes e suas contribuições para o debate apresentando seus títulos, seus autores, ${ }^{4}$ suas linhas de interpretações.

O exame da Revista Terra Livre é considerado importante porque, a partir da segunda metade da década de 1980, esta se tornou "um dos grandes representantes de sua [da Geografia brasileira] produção científica" (p. 74).

Os artigos publicados sobre o tema atingiram uma maior quantidade de leitores, isso explica a relevância que os movimentos sociais passaram a ter durante a década de 1990. No plano teórico, esta relevância caminhou rumo a uma maior acuidade no tratamento conceitual que foi dispensado aos movimentos sociais, como propostas de abordagens significativas, consubstanciadas na realidade (loc. cit., grifo nosso).

\footnotetext{
3 Todos esses textos do Boletim de Geografia Teorética também foram por nós examinados.

${ }^{4}$ Destacamos, por exemplo, Ariovaldo Umbelino de Oliveira, que publicou texto dedicado ao tema na década de 1980 neste periódico e a continuação de sua dedicação aos movimentos sociais do campo ainda hoje. O mesmo vale para a socióloga do IPPUR Ana Clara Torres Ribeiro (recém falecida) e a interlocução estabelecida com a Geografia brasileira pelo menos desde a década de 1980, como nos mostra Nelson Pedon.
} 
Dessa revista, é importante destacar aqui a predominância na década de 1990 dos estudos relacionados aos movimentos sociais no campo vinculados com a temática da reforma agrária, inversamente ao período da década de 1980 quando predominaram estudos sobre os movimentos sociais no espaço urbano.

O autor chama a atenção para o período de 1990 a 2002 em que "os movimentos sociais pouco apareceram como tema de artigos publicado na revista $\mathrm{TL}^{\prime \prime}(\mathrm{p}$. 75).Essa afirmação contradiz a citação tomada por nós acima, mas corrobora o que já vimos páginas atrás neste texto sobre o "abandono" do tema na referida década!!!!

Partimos agora para as proposições teóricas acerca dos movimentos sociais "mirados" a partir da Geografia, ainda amparados em Nelson Pedon.

Carlos Walter Porto Gonçalves nas análises que faz do avanço da fronteira econômica sobre a Amazônia e a consequente mudança nos padrões fundiários e na forma de apropriação da terra e dos recursos naturais da região verificou dois processos para ele indissociáveis: a existência e a resistência. A primeira como a afirmação da essência da vida dos grupos que aí vivem, e a segunda circunscrita no processo de embate ante aqueles que exploram, dominam e estigmatizam as comunidades da Amazônia. Daí o autor cunhar o termo "movimentos sociais de $r$ existência", ${ }^{5}$ para abarcar esse duplo processo, uma vez que a construção das identidades coletivas das populações na

\footnotetext{
${ }^{5}$ Ainda que sua proposição tenha sentido, porque prioriza a grafia do substantivo existência, o termo "r-existência" não dá a ideia do duplo processo de resistência/existência.
}

Amazônia são vinculadas a condições socioespaciais relativas à natureza (seringueiro, castanheiro, pescador), ou ainda expressa uma condição derivada da ação da expansão da fronteira econômica em seus espaços (hidrelétricas, estradas, projetos de mineração), que as transformam em atingido, assentado, deslocado.

Renato Emerson dos Santos (apud PEDON, 2009, p. 78) propõe o "raciocínio centrado no espaço", pois no seu entendimento "a ação política dos movimentos sociais atuais tem o espaço como um de seus elementos estratégicos fundamentais". Para ele, a Geografia pode ser um ponto de vista do qual é possível desvendar os estudos dos mais variados movimentos sociais. Para isso, elabora dimensões espaciais que o raciocínio centrado no espaço deve considerar e que sustentam a interpretação dos movimentos sociais. São elas: (a) A materialização/manifestação, (b) Os recortes espaciais e as construções identitárias, (c) Território e territorialidades, (d) Ação, temário e agendas, (e) Ação e interlocutores, (f) A ação e desdobramentos, impactos, efeitos, causas, origem, (g) As esferas institucionais como distintas dimensões espaço-temporais, (h) Os sujeitos da construção dos movimentos e suas experiências espaciais do fazer político.

Com esse esquema analítico o autor acredita ser possível interpretar as relações que estruturam o intrincado universo dos movimentos sociais com base nos conceitos de análise espacial.

A abordagem socioterritorial é outra contribuição da Geografia para a análise dos movimentos sociais. Elaborada por Bernardo 
Mançano Fernandes, leva em conta principalmente os movimentos sociais do campo. Seus estudos de 1996 e 1999 e também os estudos de J. Y. Martin de 1997 e 1998 concorreram para diferenciar movimentos socioespaciais e movimentos socioterritoriais. Em que ao primeiro se restringiriam as formas de mobilização social, no que a espacialidade estaria vinculada a sua capacidade de gerir determinadas demandas no âmbito de um determinado espaço, sem buscar introduzir nenhum elemento novo, seja material ou imaterial. o movimento socioterritorial, por sua vez, é uma organização que tem como objetivo criar as capacidades de introduzir novas formas de apropriação e uso dos territórios. Seu objetivo é a instauração de uma nova territorialidade. Nessa perspectiva, seriam os sindicatos exemplos de movimentos socioespaciais e os movimentos de sem terra e sem teto, movimentos socioterritoriais.

Como último exemplo de contribuições da Geografia brasileira (esta examinada por nós) acerca das tentativas teórico-conceituais visando compreender os movimentos sociais e/em sua variante espacial temos Marcelo Lopes de Souza, estudioso a quem já recorremos neste texto.

Para esse autor, entender o papel do espaço na dinâmica dos movimentos sociais faz parte de demandas especificamente brasileiras, pois elucidar a espacialidade do social é um caminho para melhor desvendar as potencialidades e limites dos movimentos. (2009, p. 16, grifo do original).

Para ele, a preocupação com o espaço parece ser uma característica dos próprios movimentos sociais da "segunda geração" dos "novos movimentos sociais urbanos".

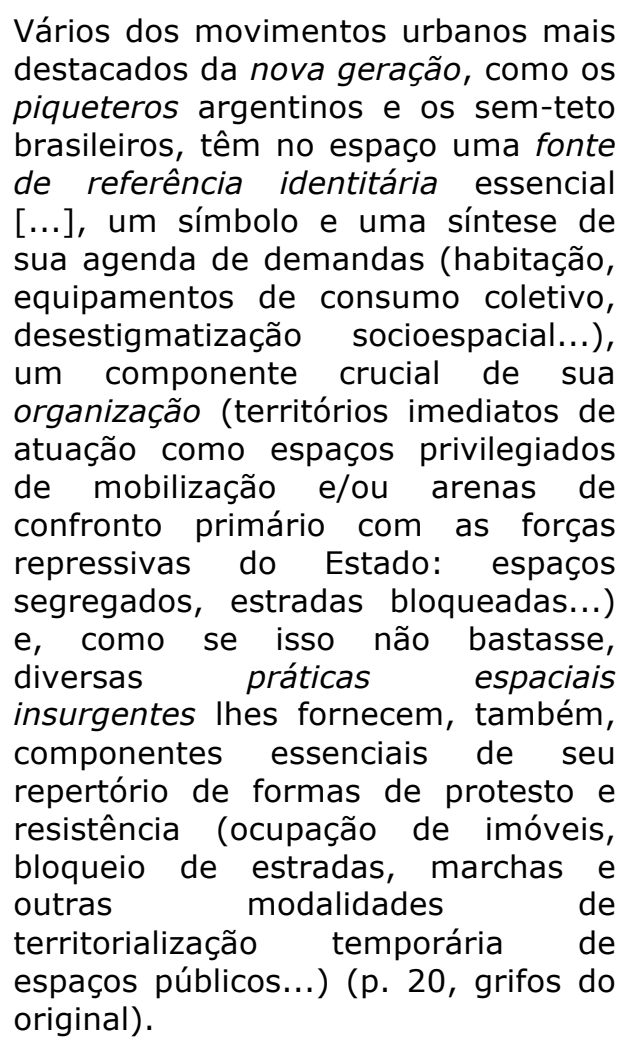

Em outro texto advoga que as mudanças e as crises teóricas contemporâneas buscam consolidar novos marcos de análises que examinem e avaliem as agendas e a práxis nos processos de mudança socioespacial (idem, 2010, p. 13).

Defende que nenhuma prática humana está alijada da dimensão espacial, mas algumas se ligam a isso fraca ou indiretamente, enquanto que outras estão ligadas a isso mais forte e diretamente, impregnadas de aspectos que vão da identidade à organização. São práticas espaciais, "práticas sociais densas de espacialidade" (loc. cit., grifo do original).

E avalia que as práticas espaciais podem servir a dois propósitos, duas chaves de interpretação: dominação ou emancipação. 
Amparado em Henri Lefebvre e sua formulação de que o espaço é ao mesmo tempo, um produto e um condicionador das relações sociais, esse autor nos adverte de que pretender mudar as relações sociais sem mudar a organização espacial seria um contra-senso. Dessa forma, mudar as relações sociais, é ao mesmo tempo também mudar o espaço social, trata-se, portanto, de uma mudança socioespacial (SOUZA, 2010, p. 22).

Pretendemos até aqui explicitar algumas contribuições da Geografia para os estudos dos movimentos sociais. Pois cremos que assim como não é possível examiná-los sem levar em conta as contribuições da Sociologia, tampouco é coerente seguirmos atentos a eles isentos ao apoio que nossa ciência nos oferece.

\section{Movimentos sociais de moradia: ação direta e institucionalização}

Iniciamos este tópico retomando empiricamente o que foi verificado a partir da revisão bibliográfica: a emergência dos novos movimentos sociais nas décadas de 1980 e 1990. Das 4 Entidades Nacionais de Luta por Moradia, ${ }^{6}$ apenas a Conam surgiu no início da década de 1980. É o que nos diz Bartíria (2012): "30 anos fez agora em janeiro! 30 anos em janeiro. Então foi em janeiro de 1982. E tem 30 anos nossa Confederação Nacional" (informação verbal). ${ }^{7}$

\footnotetext{
${ }^{6}$ Conam (Confederação Nacional das Associações de Moradores), UNMP (União Nacional de Moradia Popular), CMP (Central de Movimentos Populares), MNLM (Movimento Nacional de Luta por Moradia).

${ }^{7}$ Informação fornecida em entrevista concedida em 11 de julho de 2012.
}

Gegê destaca o processo de uma década entre o embrião da CMP e sua fundação:

A gente precisou caminhar de 1983 até 1993 enquanto Pró-Central, estudando o Estado brasileiro, estudando as lutas que aconteciam no país. Tentando conhecer o todo das lutas e tanto que em 1993, em Outubro de 1993, o ano que vem nós fazemos aniversário de 20 anos (informação verbal). ${ }^{8}$

Por sua vez, Verinha nos informa de seu ingresso na União em fins da década de 1980, e da fundação da entidade dois anos antes:

Eu entrei no Movimento em 1989, e já existia a União. Ela foi fundada em 1987. Atualmente sou da direção da União, afastada, devido a campanha eleitoral, porque sou candidata a vereadora aqui na capital ${ }^{9}$ (informação verbal). ${ }^{10}$

Chamando atenção para o ideal da luta de classe, Antônio José (2012) localiza

\footnotetext{
${ }^{8}$ Informação fornecida em entrevista concedida em 2 de agosto de 2012.

9 A título de curiosidade, a totalidade de votos obtidos por Verinha nas eleições municipais de 2012 alcançou 20.910, tendo sido mais votada que o ex-vereador Chico Macena (20.896 votos) e o ex-ministro do Esporte Orlando Silva (19.739 votos). Outra de nossas entrevistadas que também concorreu à vereança em São Paulo pelo Partido Comunista do Brasil alcançou a cifra de 2.690 votos. No entanto, nenhuma das duas foi eleita (disponível <http://divulga.tse.jus.br/oficial/index.html>, acesso em: out. 2012). Sobre a atuação dos militantes de esquerda nos movimentos e sua escalada aos espaços institucionais de maneira partidária, também aí reside uma contradição, pois no discurso das lideranças elas almejam influenciar a política para que esta seja feita de forma diferente. Intelectuais como Souza (2010) atentam para o fato de a aproximação partidária poder inclusive comprometer a autonomia dos movimentos. Gohn (2008), apoiada em Alain Touraine, questiona se não serão os próprios partidos políticos quem mais atrapalham seu fazer político e suas atividades.

10 Informação fornecida em entrevista concedida em 25 de julho de 2012.
} 
no início da década de 1990 a fundação do Movimento Nacional de Luta pela Moradia:

O Movimento Nacional surgiu em 1990, a partir de uma divergência de um sonho que se tinha anteriormente. Que nós acreditávamos que era possível a luta de classe. Não as lutas, mas a luta de classe de certa forma conviver dentro de uma mesma sala (informação verbal). ${ }^{11}$

O exposto nos remete à formulação de Gurza Lavalle, Castello e Bichir de que os novos atores continuaram em cena no referido período, e que na verdade foi o olhar da academia que passou a mirar outras configurações, que os autores denominam como nova sociedade civil, nisso os movimentos sociais passaram despercebidos das análises. Importa observar também que dentre os novos atores desta nova sociedade civil, além de ONGs e fóruns, emergiram na "década oculta" as articuladoras, tidas pelos autores como "uma espécie de sociedade civil de segundo nível, quer dizer, um conjunto de entidades constituídas por outras associações ou entidades civis" (p. 46). Não por acaso, as 4 Entidades Nacionais de Luta por Moradia, são exatamente isso, têm a função, ainda que algumas vezes limitada (GOMES, 2010), de articular os diversos e variados movimentos populares e de moradia pelo território nacional.

Retornemos a Jacobi (1989), que nos dá o contexto da criação desses movimentos no período da transição democrática: "Na conjuntura da crise do autoritarismo, a ascensão dos movimentos e das organizações políticas de oposição configura a consolidação de moradores na luta pelo direito à cidadania". Extraímos do depoimento de

\footnotetext{
11 Informação fornecida em entrevista concedida
} em 27 de junho de 2012.
Bartíria a ideia que resume não só a fundação do movimento do qual faz parte, a Conam, mas também das outras entidades no contexto da ditadura, e, além disso, marca também o início de uma forma de atuação mais ampla, perpassando os bairros nos quais estavam circunscritos tais movimentos.

E com um processo aí muito grande da ditadura, da gente não ter essa liberdade de expressão e aí quando você consegue na Constituição, a gente teve que jogar um papel fundamental que foram as nossas entidades participando desse processo da Constituição na busca de mudanças mais... de democracia pro nosso país. Nós também tivemos um papel importante porque nossas entidades começam também a se constituir mais legalmente (informação verbal). ${ }^{12}$

Vemos então que desde a fundação dos movimentos estão pautadas formas de atuação que não sejam apenas a ação direta, mas também a preocupação em fazer parte de um processo amplo, mobilizador de outras estruturas e propositivo no atendimento de suas demandas, pois como nos adverte Bartíria, buscando nossa aquiescência: "Enquanto você não for atendido por essas políticas elas continuam sendo reivindicadas, né?" (informação verbal). ${ }^{13}$

É o que nos dizem nossos entrevistados quanto à dupla estratégia de pautar suas reivindicações:

Antônio José, do Movimento Nacional:

[...] a nossa estratégia é sempre utilizar de um lado, em conjunto com outros Movimentos, inclusive os espaços institucionais de construção desse marco legal, dessa legalidade

\footnotetext{
12 Informação fornecida em entrevista concedida em 11 de julho de 2012.

13 Informação fornecida em entrevista concedida em 11 de julho de 2012.
} 
aí: vamos pensar em Conselhos, Seminário, Oficina em todos os âmbitos, de nacional a internacional, então esse é um ponto, uma frente que a gente usa como estratégia [...] E o outro é a pressão. Agora, é um caminho da pressão que não é mais aquela pressão de alguns anos atrás. Sabe, de ocupação de terra e divisão de pedaços etc. e tal. Até de ocupação sim, pode ser de terra, pode ser de prédio, mas a ocupação das instituições corresponsáveis, senão corresponsáveis, mas as responsáveis também como a Caixa Econômica (informação verbal). ${ }^{14}$

Para Verinha, da União dos

Movimentos de Moradia:

Primeira estratégia: é mobilização! Mobilização! Articulação política também é uma estratégia da União. A participação no institucional! Estou falando essa questão do institucional - eu já fui do Conselho Nacional das Cidades, então uma estratégia também é essa. Porque o Conselho Nacional das Cidades tem sido um instrumento muito importante para os quatro Movimentos e para a União em especial que hoje tem representantes em vários Estados do Brasil e que sabe o que é a autogestão, moradia mesmo (informação verbal). ${ }^{15}$

Para Jacobi (1989), analisando o significado da ação coletiva e seus efeitos político-institucionais no contexto da transição democrática no Brasil:

Muitos movimentos se tornam catalisadores de um discurso antiEstado em escala nacional, como reflexo do corte que se opera entre a sociedade civil e o Estado, que estimula a emergência de diversas formas de resistência. As mudanças políticas posteriores, que implicam um paulatino processo de redemocratização da sociedade, colocam em pauta a permanente tensão existente entre o caráter de

\footnotetext{
14 Informação fornecida em entrevista concedida em 27 de junho de 2012.

15 Informação fornecida em entrevista concedida em 25 de julho de 2012.
}

resistência do movimento social e sua institucionalização (p. 10).

$\mathrm{Na}$ visão do autor, tais movimentos não buscam transformar a sociedade, mas sim pressionar o Estado para obter respostas concretas para suas demandas. Contudo, nosso trabalho de campo mostrou que, embora as lideranças estejam absolutamente seguras dessa pressão, não é necessariamente verdadeiro que tenham abortado a missão de transformar a sociedade. Analisemos algumas falas.

Donizete, do Movimento de Moradia da Zona Oeste e Noroeste, filiado à União, referindo-se às dificuldades de andamento no Programa Minha Casa Minha Vida Entidades: "Então a dificuldade do Minha Casa Minha Vida é uma dificuldade ideológica. Minha Casa Minha Vida é uma pequena célula de um princípio socialista dentro do Capitalismo, é isto! (informação verbal). ${ }^{16} \mathrm{O}$ mesmo se verifica no discurso de Gegê:

[...] mas de qualquer forma, a CMP tem como estratégia política o que eu disse lá atrás: transformação da sociedade rumo ao socialismo, a um mundo onde não exista nem explorados, nem exploradores. Onde homens e mulheres sejam tratados de igual para igual como sujeitos na sociedade e não como objeto como hoje o sistema capitalista nos têm (informação verbal). ${ }^{17}$

Ainda que seja cada vez mais difícil combater o capitalismo. Estarão os ideais, modos de compreensão, de fabricação e acesso à habitação dos movimentos sociais de moradia ajustados em outras relações que não as capitalistas?

\footnotetext{
16 Informação fornecida em entrevista concedida em 4 de abril de 2012.

17 Informação fornecida em entrevista concedida em 2 de agosto de 2012.
} 
Sobre a oposição reforma versus transformação:

É preciso fornecer uma direção política ao movimento de forma a transcender 0 seu caráter "reformista" e permitir que ocorram avanços, através da politização das lutas. O reformismo do movimento corresponde, na visão de tais agentes, à sua incapacidade de ampliar as lutas, que permanecem muito vinculadas às demandas pontuais e específicas (asfalto, água, creche, transporte etc. ${ }^{18}$ (JACOBI, 1989 , p. 15, grifo do original).

As lutas no local de moradia foram, durante muito tempo, consideradas secundárias porque não se referiam aos conflitos diretos entre capital e trabalho ou tidas como reformistas na medida em que reivindicavam casa própria. Entendemos que a casa própria para quem nela mora tem valor de uso, é uma mercadoria de uso pessoal. Se os moradores pagarem aluguel estarão pagando a renda da mercadoria terra-edificação em parcelas mensais. Não é possível separar o lugar do viver do lugar de trabalhar sem incorrer em simplificações e não é possível considerar que a sociedade se move como querem os intelectuais (RODRIGUES, 2007, p. 16).

Para ela, é contra a condição de permanência na pobreza absoluta que os movimentos se organizam e lutam pela alteração da desigualdade espacial tornando - lugar de moradia em possibilidade de mudança que está no reconhecimento do valor de uso e no direito à urbanidade (p. 8). Para nós, se a essa dinâmica não podemos atribuir a chancela de transformação, tampouco podemos reduzi-la a reformismo.

\footnotetext{
${ }^{18}$ É exatamente o que faz a Conam. Como nos diz Bartíria: "A nossa entidade, como ela é de Associação de Moradores, ela é ampla também na sua política, porque nós não tratamos só da política da moradia. ela é da saúde, da educação, do transporte, da questão da água, do saneamento... de todas as políticas públicas, que é o que busca uma associação de moradores de um bairro, né"?
}

Sobre a relação entre a ação direta e a luta institucional, Souza (2010, p. 29) verifica que nem sempre a ação direta visa simplesmente atacar frontalmente o Estado, mas sim pressioná-lo. De "contra Estado" para "com o Estado", para que este se sente à mesa de negociações.

As lideranças dos movimentos sabem das contradições a que estão expostas ao sentar-se para negociar com o Estado, pois, como nos adverte o autor, amparado no pensamento autonomista de Castoriadis (op. cit.): "O Estado é uma estrutura heterônoma, e é por isso que não se deve acalentar qualquer ilusão em relação a ele!" (p. 25). Mas também e exatamente por essa razão está conjunturalmente sujeito a contradições, pois o mesmo Estado que, por um lado, não atende (a não ser com medidas paliativas) às suas demandas, por outro, "inaugura", ainda que com todas as limitações, ajustes a serem feitos, falhas, incompreensões, um Programa para lidar com as dificuldades estruturais das 4 Entidades Nacionais e de tudo o que elas representam. Caso não fosse assim não ouviríamos do Superintendente da Caixa Econômica Federal, Paulo Galli, em Seminário na Assembleia Legislativa para tratar da parceria entre governo federal e estadual na implementação do Programa Minha Casa Minha Vida em São Paulo:

Por meio da Caixa, não existe nenhuma resistência, nada nos impede e muito nos alegraria, muito nos entusiasmaria se a gente puder produzir mais. Há recursos para isso, há disposição da Caixa para isso, mas existem vários problemas operacionais, sistêmicos e burocráticos que os próprios movimentos têm insistentemente nos colocado e a gente tem discutido e aperfeiçoado 0 nosso processo (informação verbal). ${ }^{19}$

\footnotetext{
19 Informação fornecida em 6 de junho de 2012, em Seminário na Assembleia Legislativa de São Paulo.
} 
Do mesmo modo, não ouviríamos de uma das lideranças a compreensão que os movimentos têm das limitações do aparelho estatal no que se refere especificamente ao gerenciamento da Caixa Econômica Federal no tratamento das questões atinentes às Entidades e às construtoras:

Eles também trabalham com a contradição. Não é tão fácil quando eles têm todo um outro público e depois tem um público que é diferenciado [referindo-se aos movimentos].

As equipes da Caixa Econômica Federal, acostumadas a atender construtoras e empreiteiras, agora atendem também as Entidades. Como os propósitos, demandas, especificações técnicas, recursos etc. dos dois "grupos" são essencialmente diferentes, decorrem daí as dificuldades a que se refere Bartíria.

"O Estado não mais vê os movimentos somente como seus adversários, mas legitima suas reivindicações" (JACOBI, 1989, p. 12). É então na busca da exploração dos pontos mais vulneráveis dessa contradição que os movimentos sociais de moradia procuram explorar o que é possível: brechas legais, instâncias participativas oficiais, recursos públicos (SOUZA, p. 25). Perguntamos: a isso se chama institucionalização? Pedro Jacobi (1989, p. 12) uma vez mais nos auxilia:

A institucionalização
representa basicamente a
perspectiva de negociar e
interagir com o Estado, o que
muitas vezes tem provocado
interpretações contraditórias
sobre o caráter dos
movimentos e seu potencial
de transformação.

Se assim for, em nossa opinião isso não poderá ser tomado como algo negativo, pois se lutar por espaços políticos (no sentido estrito do termo) significar "cooptação" ou descaracterização dos movimentos, se não o fizerem, os movimentos seguirão num diálogo voltado para eles próprios, e de onde não partirão avanços como, por exemplo, aquele que vimos examinando no escopo desta investigação - o Programa Minha Casa Minha Vida Entidades, ainda que ele tenha inúmeros problemas. Mesmo que sejam necessários diversos ajustes para os quais inclusive as 4 Entidades incessantemente trabalham para aperfeiçoar.

\section{Referências bibliográficas}

CARLOS, A. F. A. O espaço urbano e os movimentos sociais. Boletim de Geografia Teorética, Rio Claro, v. 22, p. 147-153, 1992.

EVERS, T. Identidade: a face oculta dos novos movimentos sociais. Novos Estudos, São Paulo: Cebrap, v. 2, n. 4, p. 11-23, abr. 1984.

GOHN, M. G. Novas teorias dos movimentos sociais. São Paulo: Loyola, 2008.

GOMES, F. G. A Central de Movimentos Populares e os desafios da articulação dos movimentos sociais. Dissertação (Mestrado) Pontifícia Universidade Católica, São Paulo, 2010.

GURZA LAVALLE, A.; CASTELLO, G.; BICHIR, R. Quando novos atores saem de cena: continuidade e mudanças na centralidade dos movimentos sociais.

Revista Política \& Sociedade, Florianópolis: UFSC, n. 5, p. 37-55, out. 2004.

JACOBI, P. Atores sociais e Estado. movimentos reivindicatórios urbanos e Estado: dimensões da ação coletiva e efeitos político-institucionais no 
Brasil. Espaço \& Debates, São

Paulo, ano IX, n. 26, p. 10- 21, 1989.

JESUS, P. M. Movimentos sociais de moradia e o segmento de menor renda no Programa Minha Casa Minha Vida. In: Cadernos Metrópole, São Paulo: Educ, n. 31, 2014. No prelo.

LACLAU, E. Os novos movimentos sociais e a pluralidade do social. Revista Brasileira de Ciências Sociais, v. 1, n. 2, p. 41-47, out. 1986.

PEDON, N. R. A pesquisa geográfica sobre os movimentos sociais: balanço e perspectivas. Revista Terra Livre, São Paulo, ano 25 , v. 2, n. 33, p. 6784, jul./dez. 2009.

RODRIGUES, A. M. Movimentos populares urbanos e as lutas contra a segregação socioespacial. In: MARTINS, C. A.; MARTINS, S. F.; SILVA, S. M. V. (Orgs.). Quintas urbanas: conversas sobre a cidade e o urbano. 2. ed. Rio Grande, RS: NAU-FURG, 2010. p. 87-107.
. Os movimentos sociais urbanos e a questão da moradia. Boletim de Geografia Teorética, Rio Claro, v. 22, n. 44, p. 173-176, 1993.

SILVA, J. B. Movimentos sociais e Estado: implicações espaciais. Boletim de Geografia Teorética, Rio Claro, v. 22, p, 180-185, 1992.

SOUZA, M. L. Com o Estado, apesar do Estado, contra o Estado: os movimentos urbanos e suas práticas espaciais, entre a luta institucional e a ação direta. Cidades: Revista Científica, Presidente Prudente: Grupo de Estudos Urbanos, v. 7, n. $11,2010$.

A "nova geração" de movimentos sociais urbanos e a nova onda de interesse acadêmico pelo assunto. Cidades: Revista Científica, Presidente Prudente: Grupo de Estudos Urbanos, v. 6, n. 9, 2009. 